\title{
Searching for New Sources of Phytopharmaceuticals in Native Valeriana from Patagonia, Argentina
}

\section{Opinion}

The study of new sources of phytopharmaceuticals is an interesting field of research and in many cases the selection of new species to study are based on plants that have been used since ancient times by different ethnic groups in each regions of the world. One of the genus of cosmopolitan distribution with many species used for medicinal purposes around the world is Valeriana L.

The genus Valeriana, with more than 250 species is widely distributed worldwide, except Australia and New Zealand, being South America an important center of diversification. The underground organ of many Valeriana species contains numerous compounds used as a sedative and relaxing, allowing the reduction of nervousness and agitation associated with stress. This genus is widely studied, with special focus on anxiolytic properties. For these purposes, roots of the Eurasian species $V$. officinalis L. have been used worldwide for treatment of anxiety and mild sleep disorders. A study indicates that flavonoids in this species have sedative activity in the central nervous system. Others authors suggests that biochemical composition and active constituents in Valeriana are phenols, valepotriates, valeric acid and gammaaminobutyric acid. Besides, pre-clinical studies reported the antidepressant-like activity of some species as $V$. officinalis, $V$. jatamansi Jones, V. glechomifolia Mey. and V. prionophylla. Due to the importance of Valeriana species for medicinal purpose, in different countries have sought alternatives for replacement of $V$. officinalis by native representatives. Examples are $V$. edulis Nutt. ex Torr. \& A. Gray subsp. procera (Kunth) G. F. Mey in Mexico, $V$. glechomifolia in Brazil and V. jatamansi in India, among others.

In this context, from the Argentine Patagonia we started the study in native Valerians in order to search alternative sources of phytopharmaceuticals. In Argentina, the genus Valeriana is represented by 50 species, of which 20 are distributed in Patagonia. The Andean Region of Patagonia has a rich diversity of Valeriana and Patagonian indigenous peoples and rural societies extensively used some of these species since ancient times for curing various human ailments. The most used Valeriana species by regional ethnic groups is V. carnosa "Ñanculahuén", considered a "sacred plant" and the breadth of its reputed uses has led to its being known as "the plant that cures the seven illnesses". This

\begin{tabular}{l} 
Opinion \\
Volume 8 Issue 1 - 2017 \\
Nagahama $\mathbf{N}^{1 *}$, Bach $\mathbf{H G}^{2}$, Manifesto $\mathbf{M M}^{2}$, \\
Wagner $\mathbf{M}^{3}$ and Fortunato RH${ }^{1,2}$ \\
${ }^{1}$ National Council for Scientific and Technical Research \\
(CONICET), Argentina \\
${ }^{2}$ Institute of Biological Resources, Argentina \\
${ }^{3}$ Department of Pharmacology, Faculty of Pharmacobotany, \\
University of Buenos Aires, Argentina \\
*Corresponding author: Nicolás Nagahama, National \\
Council for Scientific and Technical Research (CONICET), \\
Experimental Station Agroforestal Esquel, National Institute \\
of Agricultural Technology (INTA), Chacabuco 513. 9200, \\
squel, Chubut, Argentina, Tel: +54 2945 451 558; \\
Email: nagahama.nicolas@inta.gob.ar \\
Received: July 13, 2017 | Published: July 17, 2017 \\
\hline
\end{tabular}

attribute confers on the species high cultural and symbolic value for the Mapuche people, and its reputation and use has spread throughout the formal and informal medicinal herb market of Patagonian cities. The crude drug is prepared from the roots and rhizomes, principally as a decoction and has been cited as hepatic, respiratory, circulatory, urinary, digestive, analgesic, antiinflammatory, antidepressive and for treat cultural syndromes. Studies suggest that secondary metabolites in $V$. carnosa are majority valepotriates, flavonoids, phenolic acids, essential oils, among others.

Currently, we are studying different aspects of V. carnosa, from genetic and chemical characterization of populations distributed along Patagonia, to the study of propagation and cropping systems. The objective is to study the bioactivity of chemical compounds under the paradigm of science in V. carnosa and in parallel domesticate and cultivate this species, in order to obtain potential marketable font of phytodrugs and strengthen the productive development in the region. 